\title{
Erratum to: Biofilm and Planktonic Lifestyles Differently Support the Resistance of the Desert Cyanobacterium Chroococcidiopsis Under Space and Martian Simulations
}

\author{
Mickael Baqué • Giuliano Scalzi • Elke Rabbow • \\ Petra Rettberg • Daniela Billi
}

Published online: 1 June 2014

(C) Springer Science+Business Media Dordrecht 2014

Erratum to: Origins of Life and Evolution of Biospheres DOI 10.1007/s11084-013-9341-6

The dedication on the first page of this paper should read:

"This paper is in memoriam of E. Imre Friedmann (1921-2007) and Roseli Ocampo-Friedmann (1937-2005)".

The online version of the original article can be found at http://dx.doi.org/10.1007/s11084-013-9341-6.

M. Baqué · G. Scalzi • D. Billi $(\bowtie)$

Dipartimento di Biologia, Università di Roma "Tor Vergata”, Rome, Italy

e-mail: billi@uniroma2.it

E. Rabbow $\cdot$ P. Rettberg

Institute of Aerospace Medicine, DLR, Cologne, Germany 